\title{
G protein-coupled receptor 35: an emerging target in inflammatory and cardiovascular disease
}

\author{
Nina Divorty ${ }^{1,2+}$, Amanda E. Mackenzie ${ }^{1+}$, Stuart A. Nicklin ${ }^{2}$ and Graeme Milligan ${ }^{1}$ * \\ 'Molecular Pharmacology Group, Institute of Molecular, Cell, and Systems Biology, College of Medical, Veterinary and Life Sciences, University of Glasgow, \\ Glasgow, UK \\ ${ }^{2}$ Institute of Cardiovascular and Medical Sciences, College of Medical, Veterinary and Life Sciences, University of Glasgow, Glasgow, UK
}

\section{Edited by:}

Terry Kenakin, University of North

Carolina at Chapel Hill, USA

\section{Reviewed by:}

Domenico Criscuolo, Genovax, Italy

J. M. Ad Sitsen, ClinPharMed,

Netherlands

\section{${ }^{*}$ Correspondence:}

Graeme Milligan, Molecular

Pharmacology Group, Institute of Molecular, Cell, and Systems Biology,

College of Medical, Veterinary and

Life Sciences, University of Glasgow,

Wolfson Link Building 253,

Glasgow G12 8QQ, Scotland, UK

e-mail: graeme.milligan@glasg

ow.ac.uk

these authors have contributed equally to this work.
G protein-coupled receptor 35 (GPR35) is an orphan receptor, discovered in 1998, that has garnered interest as a potential therapeutic target through its association with a range of diseases. However, a lack of pharmacological tools and the absence of convincingly defined endogenous ligands have hampered the understanding of function necessary to exploit it therapeutically. Although several endogenous molecules can activate GPR35 none has yet been confirmed as the key endogenous ligand due to reasons that include lack of biological specificity, non-physiologically relevant potency and species ortholog selectivity. Recent advances have identified several highly potent synthetic agonists and antagonists, as well as agonists with equivalent potency at rodent and human orthologs, which will be useful as tool compounds. Homology modeling and mutagenesis studies have provided insight into the mode of ligand binding and possible reasons for the species selectivity of some ligands. Advances have also been made in determining the role of the receptor in disease. In the past, genome-wide association studies have associated GPR35 with diseases such as inflammatory bowel disease, type 2 diabetes, and coronary artery disease. More recent functional studies have implicated it in processes as diverse as heart failure and hypoxia, inflammation, pain transduction and synaptic transmission. In this review, we summarize the progress made in understanding the molecular pharmacology, downstream signaling and physiological function of GPR35, and discuss its emerging potential applications as a therapeutic target.

Keywords: GPR35, orphan receptor, zaprinast, kynurenic acid, CXCL17, heart failure, hypoxia, inflammation
G protein-coupled receptors are historically the most successful group of drug targets, and account for some $30-40 \%$ of approved drugs on the market today (Drews, 2000; Hopkins and Groom, 2002; Rask-Andersen et al., 2011). Indeed, several GPCR ligands are among the worldwide 100 best-selling pharmaceutical compounds (Zambrowicz and Sands, 2003). The success of GPCRs as therapeutic targets stems from their role as transducers of extracellular signals across the cell membrane and modulators of intracellular signaling, therefore bypassing the need for membrane-permeable ligands. Many GPCRs also contribute directly to the pathophysiology of disease, making them ideal as drug targets. However, despite their success, it is estimated that only 59 of the 370 non-olfactory GPCRs have been successfully exploited as drug targets, suggesting that the remainder may play largely modulatory roles unsuitable for this purpose or that there still exists great potential within the GPCR drug development arena (Sams-Dodd, 2005; Gashaw et al., 2011; Garland, 2013).

Abbreviations: BRET, Bioluminescence Resonance Energy Transfer; $\left[\mathrm{Ca}^{2+}\right]_{\mathrm{i}}$, intracellular $\mathrm{Ca}^{2+}$; cGMP, cyclic guanosine $3^{\prime} 5^{\prime}$ monophosphate; DMR, dynamic mass redistribution; $\mathrm{EC}_{50}$, half-maximal effective concentration; eYFP, enhanced yellow fluorescent protein; GPCR, G protein-coupled receptor; GWAS, genome-wide association study; HEK, human embryonic kidney; IBD, inflammatory bowel disease; LPA, lysophosphatidic acid; qRT-PCR, quantitative reverse transcriptase PCR; SNP, single nucleotide polymorphism.
Orphan GPCRs (receptors that have not yet been associated with being activated by an endogenously produced ligand) provide a means by which to expand the repertoire of drug targets. For example, the orexin receptors, deorphanized in 1988, are the targets of the recently approved sleep-aid medication, suvorexant (Jacobson et al., 2014). Moreover, many other orphan or recently deorphanized GPCRs display therapeutically relevant tissue distribution profiles and/or have links to disease (Civelli et al., 2013; Garland, 2013). One such orphan GPCR is G protein-coupled receptor 35 (GPR35). However, despite this, in the 16 years since its discovery (O'Dowd et al., 1998), GPR35 remains poorly characterized and has been slow to amass interest. This stems from a lack of selective and potent tool compounds with which to probe GPR35 pharmacology and pathophysiology, with added complications including significant species selectivity issues (Jenkins et al., 2011, 2012; Funke et al., 2013; Neetoo-Isseljee et al., 2013) and the lack of consensus on the identity of the endogenous ligand (Mackenzie et al., 2011; Milligan, 2011). Here we provide an overview of updates in the field of GPR35 pharmacology, physiology and pathophysiology, and discuss how GPR35 is emerging as a GPCR with considerable therapeutic potential.

\section{ENDOGENOUS LIGANDS FOR GPR35}

A number of endogenous molecules have been reported to act as agonists at GPR35 (Table 1). However, a number of these show 
Table 1 | Reported endogenous ligands with activity at GPR35.

\begin{tabular}{|c|c|c|c|c|c|}
\hline Name & Structure & Action & Potency $\left(\mathrm{EC}_{50}\right)$ & Comments & Reference \\
\hline $\begin{array}{l}\text { Kynurenic } \\
\text { acid }\end{array}$ & & $\begin{array}{l}\text { Partial agonist } \\
\text { (Human) full } \\
\text { agonist (Rat) }\end{array}$ & $\begin{array}{l}\text { Human: } \mathbf{2 1 7} \mu \mathbf{M} \\
\text { Rat: } \mathbf{6 6} \boldsymbol{\mathbf { M }}\end{array}$ & $\begin{array}{l}\text { Metabolite of } \\
\text { L-tryptophan }\end{array}$ & $\begin{array}{l}\text { Wang etal. (2006), } \\
\text { Jenkins et al. (2011) }\end{array}$ \\
\hline
\end{tabular}

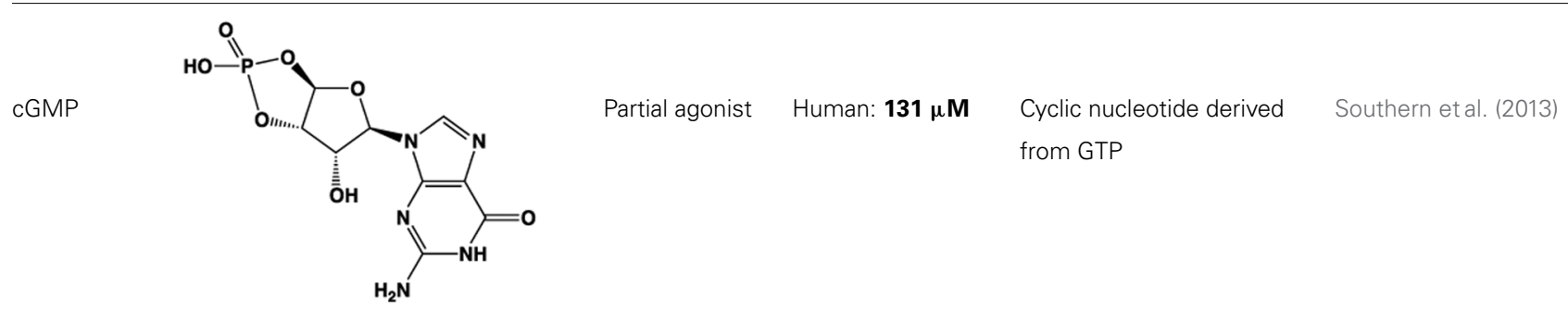

DHICA Partial agonist $\begin{aligned} & \text { Human: } 22 \mu \mathbf{M} \\ & \text { (DMR } 24 \mu \mathrm{M})\end{aligned} \begin{gathered}\text { Intermediate in the } \\ \text { biosynthesis of melanin }\end{gathered}$

\begin{tabular}{|c|c|c|c|c|c|}
\hline Reverse T3 & & Full agonist & $\begin{array}{l}\text { Human: } \mathbf{1 0 0} \mu \mathbf{M} \\
\text { (DMR } 6 \mu \mathrm{M})\end{array}$ & $\begin{array}{l}\text { Hormone produced in the } \\
\text { thyroid gland, liberated } \\
\text { from precursor T4 }\end{array}$ & Deng et al. (2012a) \\
\hline CXCL17 & Chemokine & Unknown & Not assessed & $\begin{array}{l}\text { Elevates }\left[\mathrm{Ca}^{2+}\right] \mathrm{i} \text { in a } \\
\text { pertussis toxin sensitive } \\
\text { manner }\end{array}$ & $\begin{array}{l}\text { Maravillas-Montero } \\
\text { et al. (2014) }\end{array}$ \\
\hline
\end{tabular}

Potency values in bold are those generated using a $\beta$-arrestin-2 recruitment assay. Action describes the efficacy of each ligand compared to zaprinast, if known.

modest potency at GPR35 and questions have been raised over whether they are likely to be produced at concentrations required for activation of GPR35. Moreover, some of the suggested ligands are certainly agonists at other GPCRs and/or pharma targets. An example of the latter, is LPA (mono-acylglycerol-3-phosphate). Derivatives of LPA, including 2-oleoyl LPA and 2-linoleoyl LPA, were shown to stimulate $\left[\mathrm{Ca}^{2+}\right]_{i}$ mobilization above the level of $\left[\mathrm{Ca}^{2+}\right]_{\mathrm{i}}$ produced by endogenously expressed LPA receptors in HEK 293 cells stably expressing human GPR35 (Oka et al., 2010). Since a number of other ligands that activate GPR35 have not been shown to promote coupling to the $\mathrm{G} \alpha_{\mathrm{q}}$ pathway (Jenkins et al., 2011, 2012; Mackenzie et al., 2011), this study could suggest a novel route for GPR35 stimulated signaling in which certain ligands are 'biased' in their function (Shonberg et al., 2014). However, the capacity of these $\left[\mathrm{Ca}^{2+}\right]_{\mathrm{i}}$ responses to be blocked by a GPR35 antagonist were not assessed, since no such ligands were available at that time and, therefore, this reported effect has not been intrinsically linked with GPR35 activity. Since LPA species certainly exert effects through a number of cellular proteins that form the specific sub-family of GPCRs named $\mathrm{LPA}_{1-6}$, it is unlikely that LPA acts with a potency that is selective toward GPR35 (Oka et al., 2010). Furthermore, LPA apparently does not stimulate recruitment of $\beta$ arrestin-2 to GPR35 (Southern et al., 2013), indicating that it acts in a manner distinct from the majority of other GPR35 ligands and, 
therefore, once again may display 'bias'. Since LPA is associated with numerous pathological conditions including atherosclerosis (Schober and Siess, 2012), cancer (Gotoh et al., 2012), obesity, impaired glucose homeostasis (Rancoule et al., 2014), and pain (Ueda et al., 2013), there is a need to clarify the relevance of this reported effect of LPA at GPR35.

The L-kynurenine metabolite kynurenic acid (4-oxo-1Hquinoline-2-carboxylic acid) is certainly able to promote activation of GPR35 (Wang et al., 2006). Although best known as a neuroprotective modulator through interaction with various receptors in the central nervous system (Mackenzie et al., 2011), many of these studies have not considered a role for GPR35, because early distribution studies suggested that this receptor is not highly expressed in the brain (O'Dowd et al., 1998; Wang et al., 2006). However, GPR35 has received attention as a potential modulator of the effects of kynurenic acid in the periphery (Moroni et al., 2012; Thorburn et al., 2014), although the level of kynurenic acid reported to occur in the gut and the concentration required to activate GPR35 does not appear to overlap, at least in humans (Jenkins et al., 2011; Milligan, 2011). In pharmacological assays, addition of kynurenic acid was found to mobilize $\left[\mathrm{Ca}^{2+}\right]_{\mathrm{i}}$ following transfection of GPR35 alongside a cocktail of $\mathrm{G}_{\mathrm{q}}$-based $\mathrm{G}$ protein chimeras with a $\mathrm{EC}_{50}$ of $39 \mu \mathrm{M}$ at human, $11 \mu \mathrm{M}$ at mouse, and $7 \mu \mathrm{M}$ at rat (Wang etal., 2006). Thus, a degree of species selectivity was observed between the human and rodent orthologs of GPR35 with kynurenic acid displaying higher potency at rat than at human (Wang et al., 2006). This profile was also observed in an independent study using HEK293 cells transiently expressing C-terminally manipulated forms of GPR35 and $\beta$-arrestin-2, which used a BRET assay, and generated an $\mathrm{EC}_{50}$ of $66 \mu \mathrm{M}$ for rat GPR35-eYFP and $>100 \mu \mathrm{M}$ at the equivalent human construct (Jenkins et al., 2011).

In a concerted effort to deorphanize a panel of 82 orphan GPCRs, scientists from Medical Research Council Technology and GlaxoSmithKline screened 10,500 candidate endogenous ligands using the DiscoveRx PathHunter ${ }^{\mathrm{TM}} \beta$-arrestin- 2 recruitment assay (Southern etal., 2013). In this screen, the second messenger cGMP was identified as a putative endogenous ligand of human GPR35. Subsequently, the derivatives MANT cGMP ( $2^{\prime}-O-(N$-methylanthraniloyl)-cGMP) and db-cGMP (dibutyrylcGMP) were also identified as activators of human GPR35 (Southern et al., 2013). MANT-cGMP (EC $502 \mu \mathrm{M})$ was the most potent of these, with cGMP being the least potent $\left(\mathrm{EC}_{50}\right.$ $130 \mu \mathrm{M}$; Southern et al., 2013). The functional relevance of these ligands at GPR35 remains to be demonstrated, including whether concentrations of cGMP present in vivo would be sufficient to activate GPR35. Notwithstanding, it is interesting to note that cGMP and its associated signaling pathways have received considerable attention recently for the treatment of cardiovascular disorders including hypertrophy, hypertension, ischemia, and reperfusion injury (Garcia-Dorado et al., 2009; van Heerebeek etal., 2012; Greene et al., 2013; Lukowski etal., 2014), and the possible link between GPR35 and cGMP may therefore deserve further attention.

An assessment of tyrosine pathway metabolic intermediates that contain catechol or carboxylic acid groups revealed that the melanin biosynthesis intermediate DHICA (5,6-dihydroxyindole2-carboxylic acid) and thyroid hormone synthesis intermediates T3 (3,5,3' triiodothyronine) and reverse T3 $\left(3,3^{\prime}, 5^{\prime}\right.$ triiodothyronine) promoted DMR in the human colorectal adenocarcinoma cell line HT-29 (Deng et al., 2012a). Application of the synthetic GPR35 antagonist CID-2745687 (methyl5-[(tert-butylcarbamothioylhydrazinylidene)methyl]-1-(2,4-difluorophenyl)pyrazole- 4 carboxylate) at a fixed concentration of $64 \mu \mathrm{M}$ reduced the wavelength shift of each of the aforementioned agonists to almost basal levels, indicating that their activity occurred primarily through GPR35, which is expressed endogenously in these cells. However, confirmation of these responses in an independent assay utilizing a $\beta$-lactamase reporter gene-based readout of $\beta$-arrestin recruitment suggested that only DHICA acted with similar potency to that generated in the DMR format (Deng etal., 2012a). This indicated that T3 and reverse T3, if acting through GPR35, do so in a functionally selective manner. Reverse T3 was found to be the most potent of the tyrosine metabolites assessed, generating DMR in HT-29 cells with an $\mathrm{EC}_{50}$ of $5.9 \pm 0.4 \mu \mathrm{M}$ (Deng et al., 2012a). The $\mathrm{EC}_{50}$ observed in the Tango ${ }^{\mathrm{TM}} \beta$-arrestin recruitment assay, however, was substantially higher, at $108 \pm 9 \mu \mathrm{M}$. T3 was less potent than reverse $\mathrm{T} 3$, with an $\mathrm{EC}_{50}$ of $50 \pm 5 \mu \mathrm{M}$ in the DMR assay and $513 \pm 61 \mu \mathrm{M}$ in the Tango ${ }^{\mathrm{TM}}$ assay (Deng et al., 2012a). However, estimates of the free and total levels of T3 and reverse T3 in the literature (Chopra et al., 1975; Hüfner and Grussendorf, 1978; Prescott et al., 1979) indicate that it is unlikely that the concentrations of these molecules produced in man could activate GPR35 significantly in vivo (Deng et al., 2012a). Nonetheless, it is interesting to note that the levels of reverse T3 were found to increase, and T3 to decrease, following acute myocardial infarction (Friberg etal., 2002) and in advanced heart failure (Hamilton etal., 1990), and have been utilized as a measure to predict survival rates in patients with heart disease (Iervasi et al., 2003). Thus, akin to kynurenic acid, it appears that the levels of these molecules present in the plasma of humans are below the threshold required to activate GPR35 under normal physiological conditions, although their actions at GPR35 may be relevant when plasma levels are altered, for example during disease.

The most recent suggestion of an endogenous ligand for GPR35 is perhaps the most intriguing. Maravillas-Montero et al. (2014) have shown that the chemokine CXCL17 is able to elevate $\left[\mathrm{Ca}^{2+}\right]_{\mathrm{i}}$ in both HEK293 cells transfected to express human GPR35 and in the human monocytic cell line THP-1. Moreover, effects were produced at modest concentrations of the chemokine and this ligand was able to promote chemotaxis of THP-1 cells (Maravillas-Montero et al., 2014). The authors further highlighted similarities in sequence between GPR35 and more traditional chemokine receptors, going so far as to suggest the renaming of GPR35 as 'CXCR8' (Maravillas-Montero et al., 2014).

\section{SYNTHETIC LIGANDS FOR GPR35}

Consensus may not have been reached on whether GPR35 is truly activated by any of the aforementioned endogenous ligands in vivo (Mackenzie et al., 2011; Milligan, 2011), yet progress in 
the identification of synthetic surrogate ligands for this receptor has been quite successful (Table 2). Focused compound discovery efforts carried out by both the industrial and academic sectors have reported a number of compounds that display moderate-to-high potency at GPR35, and indeed there now exists a reasonable number of tool compounds with which to probe the basic physiology and pathophysiology of this receptor. Notably, however, as observed for kynurenic acid, many of these synthetic compounds display marked species selectivity. For this reason, care must be taken when selecting the compound of choice for any form of study in rodents, because the majority of screens have been conducted initially on human GPR35 and markedly human-selective molecules will generate negative results in rodents.

One of the earliest and most useful ligands reported to have activity at GPR35 is the cGMP phosphodiesterase inhibitor, zaprinast (2-(2-propyloxyphenyl)-8-azapurin-6-one) (Taniguchi et al., 2006). Zaprinast tends to be employed as a reference agonist for GPR35 since it displays moderate-to-high potency at each of the human, mouse, and rat species orthologs (Taniguchi et al., 2006; Yang et al., 2010; Jenkins et al., 2012), and zaprinast's GPR35mediated effects can be dissected from those exerted through its inhibition of cGMP phosphodiesterases (Yoon et al., 2005; Taniguchi et al., 2006; Choi et al., 2007). Moreover, the capacity of a cGMP phosphodiesterase inhibitor to interact with GPR35 was, in part, the rationale for exploring whether cGMP might be an endogenous agonist of GPR35 (Southern et al., 2013). However, despite the wide application of zaprinast as reference agonist of GPR35, with reported potency of between 2 and $8 \mu \mathrm{M}$ at the human ortholog, concerted efforts have been taken to identify agonists with high potency at human GPR35, and ideally one that acts with similar potency at the human and rodent orthologs.

A number of ligands that acted with potencies higher than zaprinast at the human ortholog were subsequently identified. These include pamoic acid (5-nitro-2-(3-phenylproplyamino) benzoic acid), which was identified independently by two groups following screens of the Prestwick Chemical Library ${ }^{\circledR}$ (Jenkins et al., 2010; Zhao et al., 2010). However, the activity of pamoic acid at the rat and mouse orthologs, at least in the assays most often employed to screen for ligands at GPR35, is considerably lower than at human (Table 1), which prevents the use of this ligand in rodent studies (Jenkins et al., 2010, 2012; Milligan, 2011). This pattern of species selectivity was also displayed by "compound 1” (4-\{(Z)-[(2Z)-2-(2-fluorobenzylidene)-4-oxo-1,3-thiazolidin5-ylidene]methyl\}benzoic acid) (Neetoo-Isseljee etal., 2013), and PSB-13253 (6-bromo-8-(4-[(3)H]methoxybenzamido)-4oxo-4H-chromene-2-carboxylic acid) (Funke et al., 2013), which both display potency similar to pamoic acid at human GPR35 and act with significantly lower potency and efficacy at the rodent orthologs (Table 1). Compound 1 was identified following a screen of the Medical Research Council Technology 100,000 small molecule compound collection using the DiscoveRx enzyme complementation $\beta$-arrestin-2 recruitment assay (Neetoo-Isseljee etal., 2013), as were four other, chemically distinct, GPR35 agonists that display various profiles of species selectivity (Neetoo-Isseljee et al., 2013), while PSB-13253 was derived from a medicinal chemistry program based on derivatives of chromen-4-one-2-carboxylic acid (Funke etal., 2013).

The study by Funke etal. (2013) also presented the first comprehensive assessment of the structure-activity relationship between various chemical structures at human, mouse, and rat orthologs of GPR35. Although noted previously for individual ligands (Neetoo-Isseljee et al., 2013), this study provided collective evidence that GPR35 ligands act with either human-selective, human-and-mouse-selective, human-and-rat-selective or rodentselective properties, with no ligands found to act with high and equal potency at all three orthologs (Funke etal., 2013). However, shortly after this study was published, two mast cell stabilizers were found to activate human and rat GPR35 in a high and equipotent manner, becoming the first tool compounds reported that could feasibly be employed to translate the findings obtained for the human receptor in vitro into in vivo physiological studies in rat models of physiology and disease (Mackenzie et al., 2014). In the BRET-based $\beta$-arrestin2 recruitment assay, lodoxamide (2,2'-[(2-chloro-5-cyano-1,3phenylene)diimino] bis[2-oxoacetic acid]) and bufrolin (6-butyl4,10-dioxo-1,7-dihydro-1,7-phenanthroline-2,8-dicarboxylic acid) activated GPR35 with respective EC50s of $3.6 \mathrm{nM}$ and $12.5 \mathrm{nM}$ at human and $12.5 \mathrm{nM}$ and $10 \mathrm{nM}$ at rat (Mackenzie et al., 2014). This study also identified a number of mast cell stabilizers that act with rat-selectivity at GPR35 orthologs, including amlexanox and pemirolast (Table 3 ).

\section{RECEPTOR HOMOLOGY MODELING EFFORTS INDICATE THAT THE BINDING POCKETS OF HUMAN AND RAT GPR35 ARE DISTINCT}

Over the past 16 years, the lack of highly potent and speciesequipotent tool compounds has greatly hindered progress in the elucidation of GPR35 function. However, assessment of the pharmacological differences between species has been useful in characterizing the ligand binding pocket of this GPCR. This approach was taken by Mackenzie et al. (2014), who used the differences in species selectivity at GPR35 to identify residues involved in ligand function. Based on the knowledge that the majority of GPR35 ligands contain at least one carboxyl group (Jenkins et al., 2010; Deng et al., 2011b, 2012b; Deng and Fang, 2012; Funke et al., 2013; Thimm etal., 2013), or a bioisostere of a carboxyl group (Mackenzie et al., 2014), it was postulated that positively charged residues within the generic ligand binding pocket of GPR35 that differed between human and rat might mediate the differences in potency. To this end, "species swap" mutations were carried out to switch key arginine residues positioned within proposed ligand binding regions (Venkatakrishnan et al., 2013) to the equivalent non-arginine residue in the opposite species ortholog. Mutagenesis efforts using these species swap mutations indicated that arginine residues present in extracellular loops 2 and 3 (or at the very top of transmembrane domain helices 6 and 7 (R164, R6.58, R7.32)) were important for ligandinduced $\beta$-arrestin-2 recruitment to human GPR35, while rat GPR35 was dependent on the species-conserved residue R4.60 at the extracellular end of transmembrane domain 4 (Mackenzie et al., 2014). 
Table 2 | Potent synthetic ligands with activity at GPR35.

\begin{tabular}{|c|c|c|c|c|c|}
\hline Name & Structure & Action & $\begin{array}{l}\text { Potency } \\
\left(\mathrm{EC}_{50} / \mathrm{IC}_{50}\right)\end{array}$ & Comments & Reference \\
\hline $\begin{array}{l}\text { Zaprinast, M\&B } \\
22,948\end{array}$ & & Full agonist & $\begin{array}{l}\text { Human: } \mathbf{2 - 8} \boldsymbol{\mu} \mathbf{M} \\
\text { Mouse: } \mathbf{1} \boldsymbol{\mu} \mathbf{M} \\
\text { Rat: } \mathbf{1 0 0} \mathbf{n M}\end{array}$ & $\begin{array}{l}\text { Xanthine derivative; cGMP PDE } \\
5,6,9 \text { inhibitor, selective for } \\
\text { PDE } 5 \text { (IC } 50750 \mathrm{nM})\end{array}$ & $\begin{array}{l}\text { Taniguchi etal. (2006), } \\
\text { Jenkins etal. (2012) }\end{array}$ \\
\hline Pamoic acid & & $\begin{array}{l}\text { Partial agonist at } \\
\text { human, weak } \\
\text { activity at rodent }\end{array}$ & 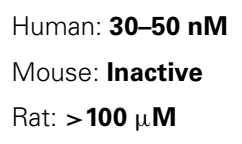 & $\begin{array}{l}\text { Added as an "inert" substance } \\
\text { to pharmaceutical agents; } \\
\text { inhibits DNA pol } \beta\left(\mathrm{IC}_{50} 9 \mu \mathrm{M}\right)\end{array}$ & $\begin{array}{l}\text { Jenkins et al. (2010, } \\
\text { 2012), Neubig (2010), } \\
\text { Zhao et al. (2010) }\end{array}$ \\
\hline
\end{tabular}

PSB-13253<smiles>COc1ccc(C(=O)Nc2cc(Br)cc3c(=O)cc(C(=O)O)oc23)cc1</smiles>

\section{Full agonist at} human, partial agonist at rat
Human: 12 nM Mouse: Inactive

Rat: $1.4 \mu \mathbf{M}$
Novel ligand; $\left[{ }^{3} \mathrm{H}\right]$ radiolabelled structure also available with $K_{D}$ of $5.3 \mathrm{nM}$
Funke etal. (2013),

Thimm etal. (2013)

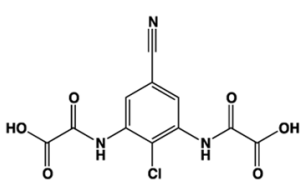

Full agonist
Human: 4 nM

Rat: 13 nM
Mast cell stabilizer; ophthalmic solution: Alamide $®$ lodoxamide tromethamine, U-42,585E
Mackenzie et al.

(2014)

74917

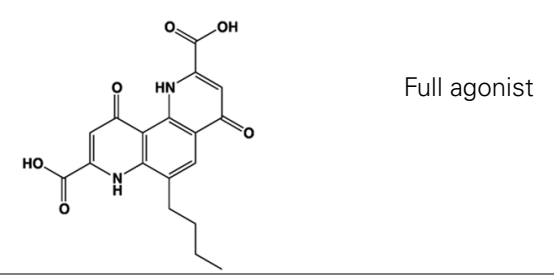

Full agonist

Bufrolin

BRL10833
Human: 13 nM

Rat: 10 nM
Mast cell stabilizer; equipotent

at human and rat GPR35
Mackenzie et al.

(2014)
Inverse agonist Human: $\sim 25$ nM Novel ligand; displays marked

selectivity toward human

GPR35
Heynen-Genel et al. (2010), Jenkins et al.

(2012) 
Table 2 | Continued

\begin{tabular}{|c|c|c|c|c|c|}
\hline Name & Structure & Action & $\begin{array}{l}\text { Potency } \\
\left(E_{50} / \mathrm{IC}_{50}\right)\end{array}$ & Comments & Reference \\
\hline $\begin{array}{l}\text { CID-2745687, } \\
\text { SPB05142, } \\
\text { ML194 }\end{array}$ & & Inverse agonist & Human: 〜200 nM & $\begin{array}{l}\text { Novel ligand; displays marked } \\
\text { selectivity toward human } \\
\text { GPR35 }\end{array}$ & $\begin{array}{l}\text { Zhao et al. (2010), } \\
\text { Heynen-Genel et al. } \\
\text { (2011), Jenkins et al. } \\
\text { (2012) }\end{array}$ \\
\hline
\end{tabular}

Potency values in bold are those generated using a $\beta$-arrestin-2 recruitment assay. Action describes the efficacy of each ligand compared to zaprinast, if known.

Receptor homology modeling efforts based on the proteaseactivated receptor 1 structure (the most closely related GPCR to GPR35 for which an atomic level structure is known) indicated that the species-equipotent ligands behaved like human-selective ligands at the human receptor and rat-selective ligands at the rat receptor (Mackenzie et al., 2014), i.e., in order to generate an equipotent response the ligand must bind differently to each ortholog (Figure 1). A number of similar residues were implicated in GPR35 ligand binding in an independent study, in which alanine substitutions were generated at putative ligand-binding residues, and the resulting mutants functionally assessed in a number of distinct assay formats including $\beta$-arrestin- 2 translocation, extracellular-signal regulated kinase phosphorylation and calcium mobilization (Zhao et al., 2014). In conjunction with receptor homology modeling efforts based on the $\beta_{2}$-adrenoceptor, arginine residues at positions $4.60,164,167$, and 6.58 were found to be involved in the binding and/or function of zaprinast and pamoic acid at human GPR35 (Zhao et al., 2014).

\section{GPR35 COUPLES TO BOTH $\mathrm{G} \alpha_{\mathrm{i} / \mathrm{o}}$ AND $\mathrm{G} \alpha_{13}$ SUBUNITS AND RECRUITS $\beta$-ARRESTIN-2}

Alongside efforts to understand the mode of ligand binding to GPR35, downstream signaling and responses following GPR35 activation have been studied in an attempt to characterize pathways in which the receptor is involved and, thereby, understand the physiology and function of the receptor. Several signaling mediators that directly interact with GPR35 have been identified, and provide insight into the pathways and responses that could potentially be targeted through its pharmacological manipulation.

In terms of classical GPCR signaling, GPR35 appears to couple to various $\mathrm{G} \alpha$ subunits depending on the cell type and/or background species. Kynurenic acid-induced binding of $\left[{ }^{35} \mathrm{~S}\right]-\mathrm{GTP} \gamma \mathrm{S}$ induced by human GPR35 heterologously expressed in Chinese hamster ovary cells was inhibited by Bordetella pertussis toxin (Pertussis toxin), which is known to specifically disrupt coupling to $\mathrm{G} \alpha_{\mathrm{i} / \mathrm{o}}$ family $\mathrm{G}$ proteins (Wang et al., 2006). Furthermore, Ohshiro etal. (2008) demonstrated that in Chinese hamster ovary cells transfected with rat GPR35, kynurenic acid and zaprinast both inhibited forskolin-induced cyclic adenosine $3^{\prime} 5^{\prime}$ monophosphate (cAMP) generation, also indicating an involvement of one or more adenylate cyclase-inhibiting $G \alpha_{i} / \mathrm{o}$ family $\mathrm{G}$ proteins. GPR35dependent effects on N-type calcium channels in rat neurons heterologously expressing human GPR35 have also been shown to be sensitive to Pertussis toxin (Guo et al., 2008). It is also interesting in this regard that the recent demonstration of CXCL17 as a potential GPR35 agonist indicated that both chemotaxis of HTP-1 cells and elevation of $\left[\mathrm{Ca}^{2+}\right]_{\mathrm{i}}$ levels in HEK293 cells transfected with the human ortholog of GPR35 were also blocked by pretreatment of the cells with Pertussis toxin (Maravillas-Montero et al., 2014).

As well as such effects, coupling to the $\mathrm{G} \alpha_{13}$ subunit, which activates guanine nucleotide exchange factors that promote GTP exchange to activate Rho family GTPases (Tanabe et al., 2004), has been observed in a human cell line. Zaprinast-induced activation of $\mathrm{G} \alpha_{13}$ was demonstrated using an activation state-sensing GTP-G $\alpha_{13}$ antibody in transfected HEK293 cells (Jenkins et al., 2011). This was observed for human GPR35 and for rat GPR35. The same study also demonstrated the ability of zaprinast to induce $\left[\mathrm{Ca}^{2+}\right]_{\mathrm{i}}$ increases in HEK293 cells co-transfected with a chimeric $\mathrm{G} \alpha_{\mathrm{q}} / \mathrm{G} \alpha_{13}$ G protein subunit and either human or rat GPR35, an effect that was specific for the $\mathrm{G} \alpha_{13}$ chimera compared with the related $G \alpha_{12}$ subunit. However, no direct coupling to the $\mathrm{G}_{\mathrm{q}} / \mathrm{G}_{11}$ group of $\mathrm{G}$ proteins, that are the routine transducers of phospholipase $\mathrm{C} \beta_{1}$-mediated elevation of $\left[\mathrm{Ca}^{2+}\right]_{i}$ has been reported. The findings of specific roles for $\mathrm{G}_{13}$ are especially interesting considering that GPR55, the receptor phylogenetically closest to GPR35, also displays this unusual coupling specificity (Ryberg et al., 2007). Thus, the canonical G protein-mediated cellular and biological effects of GPR35 appear to be largely mediated by either $G \alpha_{i / 0}$ or $G \alpha_{13}$ pathways. However, it is also possible that $\mathrm{G}$ protein coupling effectiveness might be dependent on additional factors that have yet to be explored systematically, such as ligand bias or $\mathrm{G} \alpha$ subunit expression. The possibility of ligand bias is particularly interesting in the context of GPR35 as a therapeutic target because, once deciphered, this feature could be exploited to increase the specificity of drug-induced responses. At present, current findings provide a basis for further study of these $G$ protein-mediated pathways in the search for a function for GPR35.

As well as initiating $G$ protein-dependent responses, GPR35 has been shown to directly recruit $\beta$-arrestin- 2 upon stimulation with various agonists, including kynurenic acid and zaprinast (Jenkins et al., 2010). This is followed by agonist-dependent internalization of the receptor, which is presumably mediated by $\beta$-arrestin- 2 as per the classical model for GPCR desensitization (Goodman et al., 
Table 3 | Selection of other synthetic GPR35 ligands.

\begin{tabular}{|c|c|c|c|c|c|}
\hline Name & Structure & Action & Potency $\left(E_{50}\right)$ & Comments & Reference \\
\hline $\begin{array}{l}\text { Amlexanox, } \\
\text { Amoxanox, } \\
\text { AA-673 }\end{array}$ & & Partial agonist & $\begin{array}{l}\text { Human: } \mathbf{4} \boldsymbol{\mu} \mathbf{M} \\
\text { Rat: } \mathbf{2 3} \mathbf{n} \mathbf{M}\end{array}$ & $\begin{array}{l}\text { Mast cell stabilizer; } \\
\text { anti-asthma and } \\
\text { anti-allergy medication; } \\
\text { used to treat aphthous } \\
\text { ulcers (Aphthasol尺); } \\
\text { inhibits TBK1 and IKK- } \varepsilon\end{array}$ & $\begin{array}{l}\text { Neetoo-Isseljee et al. } \\
\text { (2013), Reilly et al. (2013), } \\
\text { Southern et al. (2013), } \\
\text { Mackenzie et al. (2014) }\end{array}$ \\
\hline $\begin{array}{l}\text { Cromolyn, } \\
\text { sodium } \\
\text { cromoglicate, } \\
\text { DSCG }\end{array}$ & & Full agonist & $\begin{array}{l}\text { Human: } \sim \mathbf{7} \boldsymbol{\mu} \mathbf{M} \\
\text { Mouse: } 22-56 \mu \mathbf{M} \\
\text { Rat: } \sim \mathbf{4} \boldsymbol{\mu} \mathbf{M}\end{array}$ & $\begin{array}{l}\text { Mast cell stabilizer, } \\
\text { prophylactic agent } \\
\text { against asthma attacks } \\
\text { (Intal®); mast cell } \\
\text { stabilizer and ophthalmic } \\
\text { solution (Opticrom®) }\end{array}$ & $\begin{array}{l}\text { Yang et al. (2010), Jenkins } \\
\text { etal. (2010), Deng etal. } \\
\text { (2012a), Mackenzie etal. } \\
\text { (2014) }\end{array}$ \\
\hline
\end{tabular}

Doxantrazole<smiles>O=C1c2ccccc2S(=O)(=O)c2cc(-c3nnn[nH]3)ccc21</smiles>

Partial agonist

at human, full

agonist at rat
Human: $3.4 \mu \mathbf{M} \quad$ Mast cell stabilizer

Rat: $\mathbf{3 0 0} \mathbf{n M}$

Mackenzie et al. (2014)

Partial agonist

Human: $8.3 \mu \mathrm{M}$

Loop diuretic; congestive

Yang etal. (2012),

$\left(\left[\mathrm{Ca}^{2+}\right] \mathrm{i}\right)$

heart failure and edema

treatment; anti-asthma,

anti-inflammatory agent
Neetoo-Isseljee et al.

(2013)

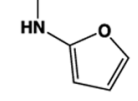

Full agonist

Human: Inactive

Rat: 95 nM
Mast cell stabilizer, ophthalmic solution

pemirolast potassium

(Alamast®)

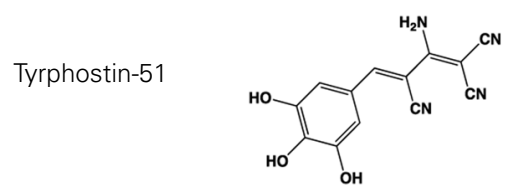

YE210
Full agonist
Human: $8 \boldsymbol{\mu} \mathbf{M}$
(DMR $120 \mathrm{nM}$ )
Identified from a library

Deng etal. (2011a)

of kinase inhibitors;

prevents tyrosine

phosphorylation

Mackenzie et al. (2014)

m




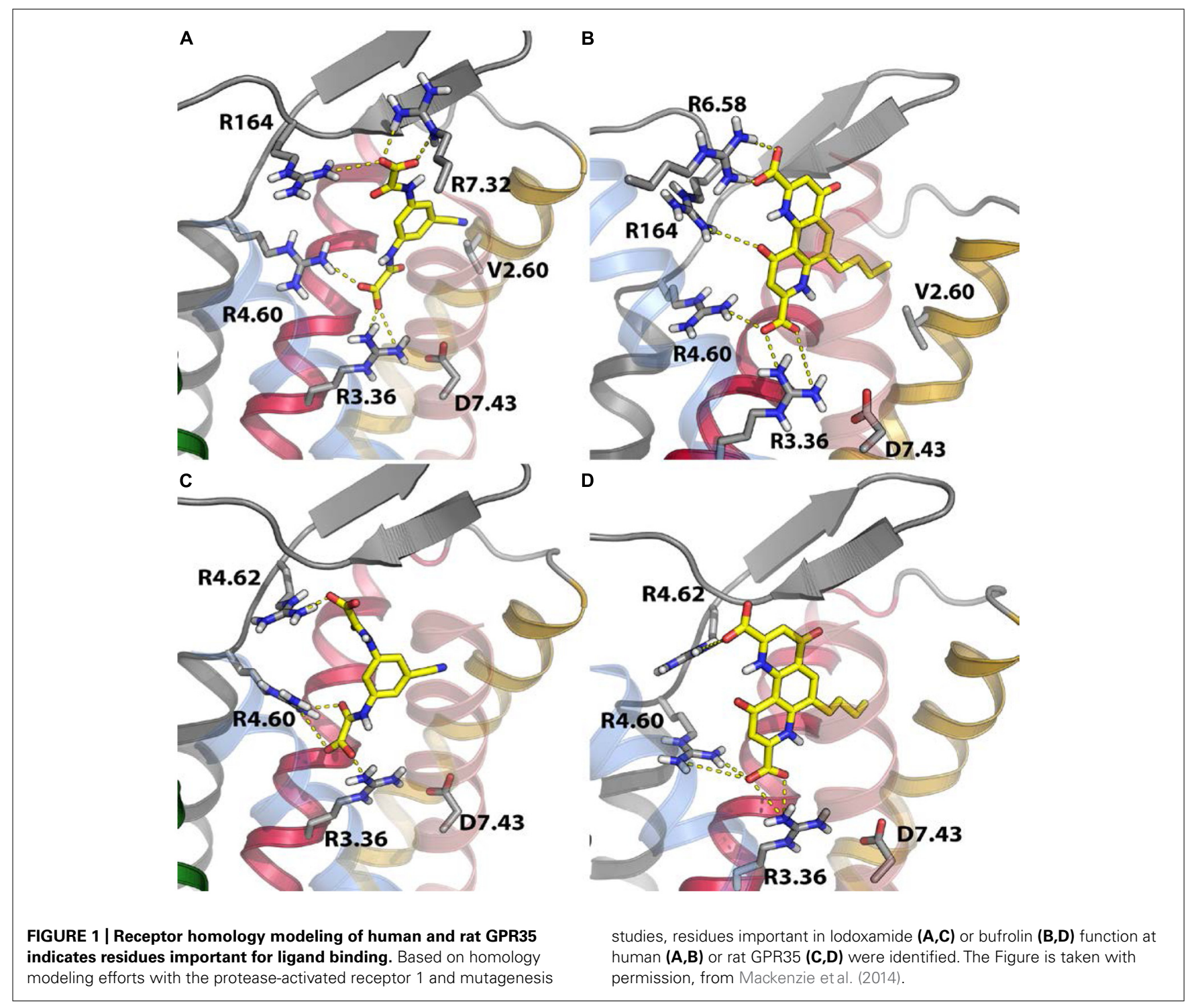

1996; Mackenzie et al., 2014). For many GPCRs, $\beta$-arrestins have now also been shown to function as signaling scaffolds, interacting with a number of different pathways including the c-Jun $\mathrm{N}$-terminal kinase, protein kinase B and cAMP pathways, but most notably the extracellular signal-regulated kinase (ERK1/2) pathway (Luttrell and Gesty-Palmer, 2010), in a G protein-independent manner. Whether this is the case for GPR35 remains to be determined, but given the diversity of processes seemingly influenced by GPR35, discussed below, screening for biased ligands may be key to understanding the physiological functions of this receptor and harnessing it as a therapeutic target.

\section{GPR35 AS A THERAPEUTIC TARGET}

Amid uncertainty regarding the endogenous ligand of GPR35 and the complex nature of its $G$ protein coupling profile, its physiological function and importance remain poorly understood. In recent years, however, the receptor has been associated with a range of diseases spanning multiple biological systems, which hints at its far-reaching potential as a therapeutic target. It will therefore be necessary to elucidate the physiological role of GPR35, both in health and disease, in order to utilize what we know of its pharmacology to develop it as a novel drug target.

\section{EXPRESSION PATTERN}

GPR35 mRNA transcripts have been detected in a number of diverse tissues throughout the body in both rodent and human studies. The publication that first identified GPR35 attempted to investigate tissue distribution through Northern blot analysis on various human and rat tissues (O'Dowd et al., 1998). Although no data were shown, the authors reported that mRNA expression was detected in rat intestine but that this was not replicated in human tissue (O'Dowd et al., 1998). Using the more sensitive approach of qRT-PCR, Wang et al. (2006) detected mRNA in lung, stomach, small intestine, colon, and spleen in both human and mouse tissues, and in human peripheral lymphocytes. In situ hybridization with GPR35 RNA probes in a mouse tissue array 
revealed expression throughout the lower digestive tract, with hybridization in the duodenum, jejunum, ileum, cecum, colon, and rectum (Wang et al., 2006). Similarly, qRT-PCR in rat detected high levels of GPR35 mRNA in lung, stomach, small intestine, and colon, but also skeletal muscle, dorsal root ganglion and uterus, with moderate expression in spinal cord, heart, liver, bladder, whole brain, and cerebrum (Taniguchi et al., 2006). Expression in the rat spinal cord and dorsal root ganglion has since been corroborated (Ohshiro et al., 2008; Cosi et al., 2011), as well as expression in mouse astrocytes (Berlinguer-Palmini et al., 2013). Finally, GPR35 mRNA has also been found in various human immune cells, including mast cells, basophils, and eosinophils (Yang et al., 2010), and invariant natural killer-like T cells (Fallarini et al., 2010).

\section{GASTROINTESTINAL AND METABOLIC DISEASES}

Based on the high expression levels of GPR35 in the gastrointestinal tract, it seems logical that the receptor should have a function in gut homeostasis. Indeed, GPR35 has been proposed as a risk factor for chronic inflammatory disorders of the gut such as IBD and ulcerative colitis. The first such report comprised a GWAS for early onset IBD (including Crohn's disease and ulcerative colitis), which identified a GPR35 SNP associated with ulcerative colitis (Imielinski et al., 2009). The SNP at rs4676410 is an upstream intron variant of GPR35 encoding a cytosine to thymine substitution, although no change in GPR35 expression was observed in tissue from individuals with IBD compared with that from genetically related controls. However, the same SNP was also associated with CAPN10, KIF1A, and RNPEPL1 genes in a linkage disequilibrium block, and CAPN10, which encodes the calciumregulated intracellular cysteine protease calpain 10, was found to be expressed at significantly lower levels in individuals with ulcerative colitis.

Prior to the IBD GWAS, the neighboring genes CAPN10 and GPR35 had both previously been linked with disease in a GWAS for type 2 diabetes mellitus (Horikawa et al., 2000). This study identified four non-synonymous SNPs in the coding region of GPR35, with only 'UCSNP-38', which encodes a serine to arginine substitution at amino acid position 294, showing an association with type 2 diabetes. However, no evidence of linkage was found for GPR35, whereas 'UCSNP$43^{\prime}$ in CAPN10 displayed both association with type 2 diabetes and evidence for linkage. The study therefore concluded that the genetic variation in CAPN10, and not GPR35, was responsible for the disease susceptibility, and no further evidence for a role of GPR35 in type 2 diabetes has since been reported.

A more recent study into ulcerative colitis and primary sclerosing cholangitis, a chronic cholestatic liver disease, has further suggested involvement of GPR35 in IBD (Ellinghaus et al., 2013). The majority of primary sclerosing cholangitis patients have concurrent ulcerative colitis, and integrated analysis of GWAS studies for both diseases identified two GPR35 SNPs as having a significant association with primary sclerosing cholangitis (Ellinghaus etal., 2013). One of these was the rs4676410 upstream intron variant previously identified in the IBD GWAS (Imielinski et al., 2009), whereas the other, at rs3749171, encodes a methionine to threonine substitution in the third transmembrane domain of the receptor. The authors of this study speculated that, due to its expression pattern and the presence of kynurenic acid both in bile and in the gastrointestinal tract in disease (Forrest et al., 2003; Paluszkiewicz et al., 2009), GPR35 may have a role in the regulation of inflammation in the gastrointestinal and biliary tracts, although this is yet to be examined experimentally.

\section{CARDIOVASCULAR DISEASE}

Although a role for GPR35 in cardiovascular disease is not immediately obvious from its expression profile, the receptor has been implicated, both directly and indirectly, in several aspects of cardiovascular dysfunction. The first study to suggest a cardiovascular role for GPR35 was a GWAS of hypertensive individuals, which aimed to identify novel predictors of coronary artery disease (Sun et al., 2008). This study identified an association between a nonsynonymous GPR35 SNP and coronary artery calcification, a risk factor in atherosclerosis and coronary artery disease. Interestingly, the identified rs3749172 SNP was the same one previously associated with type 2 diabetes (Horikawa et al., 2000). The SNP causes a serine to arginine substitution at amino acid position 294 in the receptor C-terminal tail, the primary domain involved in binding cytoplasmic proteins other than $G$ proteins. The polymorphism may therefore influence $\beta$-arrestin-mediated responses and consequently alter the selectivity of the G protein- versus $\beta$ arrestin-dependent response. In vitro observations, however, do not support this hypothesis; the serine to arginine substitution was found not to alter the potency of a range of ligands in a PathHunter human GPR35- $\beta$-arrestin-2 interaction assay (Mackenzie et al., 2014). However, as serine 294 is a potential site of ligandregulated phosphorylation, the importance of this SNP is certainly worthy of further investigation, not least because this variation is exceptionally common (reported minor allele frequency 0.494).

Further evidence of an involvement of GPR35 in cardiovascular disease was found in a global gene expression microarray analysis of twelve individuals diagnosed with chronic heart failure (Min et al., 2010). GPR35 expression in myocardial tissue from heart failure patients was significantly upregulated compared with that in healthy controls, and GPR35 was among twelve genes selected for follow-up analysis based on its orphan status and its novelty as a potential therapeutic target. Adenovirus-mediated overexpression of GPR35 in primary rat cardiomyocytes resulted in reduced viability and cellular hypertrophy (Min et al., 2010). Measuring the hemodynamic parameters of GPR35 knockout mice using a Millar catheter revealed a significant $37.5 \mathrm{mmHg}$ increase in blood pressure in the knockout mice compared with wild type littermates, which strongly implicates GPR35 in blood pressure regulation (Min et al., 2010).

A more detailed investigation of GPR35 expression in neonatal mouse cardiomyocytes found both mRNA and cell surface protein levels to increase in response to hypoxia and hypoxia-inducible factor 1 activation (Ronkainen et al., 2014). Considering that hypoxia is a feature of most chronic cardiac pathologies, this provides a possible rationale for the apparently broad involvement of GPR35 in cardiovascular disease. In the same study, overexpression of 
GPR35 in neonatal mouse cardiomyocytes led to membrane ruffling and formation of retraction fibers, but no change in cell size. This conflicts with the previous finding by Min et al. (2010) in rat cardiomyocytes, suggesting possible species variation in the specific cellular effects of GPR35. Nonetheless, both results implicate GPR35 in regulation of actin cytoskeletal rearrangements. This is very likely to be mediated through the receptor's coupling to $\mathrm{G} \alpha_{13}$ and its effector RhoA, which are well-established regulators of actin cytoskeletal remodeling (Siehler, 2009; Thumkeo et al., 2013).

In mouse surgical models of both acute hypoxia due to myocardial infarction and chronic pressure overload (a model of cardiac hypertrophy and heart failure), GPR35 expression is induced early on in the heart (after 1 day and 2 weeks, respectively; Ronkainen etal., 2014). In the chronic model this was found to precede pathological cardiac remodeling and the development of heart failure. These findings strongly suggest a role for GPR35 in cardiac pathophysiology, although further research is required to validate it as a therapeutic target in this context. Taken together, the human and mouse studies highlight potential uses for GPR35 as a predictive marker in the development of heart failure and as a target in the treatment of hypertension.

\section{IMMUNE HEALTH AND INFLAMMATION}

GPR35 has been linked to inflammation, primarily in studies in which addition of GPR35 agonists has attenuated inflammatory processes, leading to the suggestion that GPR35 can modulate inflammatory conditions. GPR35 has been linked to immune health through dietary intake and digestion of tryptophancontaining foods such as red meat, fish, eggs, and vegetables, which are broken down to generate serotonin, melanin, kynurenic acid and nicotinamide, amongst others (Thorburn et al., 2014). In the gut, kynurenic acid can be liberated from dietary protein through the activity of Escherichia coli and transported to the extracellular milieu and blood where it elicits broadly antiinflammatory effects (Kuc et al., 2008). Kynurenic acid was found to attenuate lipopolysaccharide-induced tumor necrosis factor$\alpha$ secretion in human peripheral blood mononuclear cells and purified peripheral blood monocytes (Wang et al., 2006). In an independent study, kynurenic acid treatment of monocytes and neutrophils induced firm arrest of intracellular adhesion molecule 1-expressing monolayers of human umbilical vein endothelial cells (Barth et al., 2009). This signal was diminished by Pertussis toxin treatment and reduced by small hairpin-RNA delivery targeting GPR35, implicating GPR35 as a direct mediator of leukocyte adhesion (Barth et al., 2009). However, the potency of kynurenic acid in these studies was markedly higher than in any study reported to date that has employed transfection of the receptor into a heterologous cell background. In invariant natural killerlike $\mathrm{T}$ cells, which are involved in the maturation of dendritic cells and regulation of autoimmunity, kynurenic acid and zaprinast were shown to reduce interleukin- 4 release into the culture medium in a dose-responsive and Pertussis toxin-sensitive manner without significantly reducing levels of interferon- $\gamma$, although the physiological significance of this is unclear (Fallarini et al., 2010).
In addition to studies based on kynurenic acid-induced effects, Yang et al. (2010) demonstrated GPR35 upregulation in response to challenge with IgE antibodies. The same study reported potency of anti-allergic, anti-asthma drugs cromolyn disodium and nedocromil sodium at GPR35, and an independent study also reported potency of several related mast cell stabilizers (Tables 2 and 3; Mackenzie et al., 2014). These studies suggest GPR35 may be involved in inflammation mediated by the innate immune response, and could potentially be targeted in the treatment of inflammatory conditions or autoimmunity, although a much more detailed understanding of the receptor's role is required.

The recent report proposing GPR35 to be a chemokine receptor also suggests a role for GPR35 in the immune system (MaravillasMontero et al., 2014). In this study, CXCL17 was shown to induce $\mathrm{a}\left[\mathrm{Ca}^{2+}\right]_{\mathrm{i}}$ flux in a mouse pro-B cell line transfected with GPR35. CXCL17 is a macrophage chemoattractant, and is upregulated in idiopathic pulmonary fibrosis (Burkhardt et al., 2012). GPR35 expression, along with that of macrophage markers, was found to be significantly reduced in the lungs of CXCL17 knockout mice, suggesting that GPR35-expressing macrophages require CXCL17 to migrate to the lungs, where they may play a role in inflammation (Maravillas-Montero et al., 2014). However, this is an isolated report that conflicts with some previous findings; therefore further investigation into this potential role for GPR35 is necessary.

\section{THE CENTRAL NERVOUS SYSTEM AND NOCICEPTION}

$G$ protein-coupled receptor 35 has also been suggested to have actions in the central nervous system following reports of its expression in rat spinal cord and dorsal root ganglion neurons (Ohshiro et al., 2008; Cosi et al., 2011; Moroni et al., 2012). Expression in dorsal root ganglion coincided with expression of transient receptor potential vanilloid subtype 1, a nociceptive neuronal marker (Ohshiro et al., 2008). Once again, kynurenic acid and zaprinast were shown to inhibit forskolininduced cAMP production in a Pertussis toxin-sensitive manner in these neurons, implicating the GPR35/G $\alpha_{i / o}$ axis as a potential target in the treatment of pain. In a mouse "writhing test" pain model, pre-treatment with the kynurenic acid precursor L-kynurenine or zaprinast significantly reduced the number of writhes by $58 \%$ and $54 \%$, respectively (Cosi etal., 2011). GPR35, therefore, may be useful as an antinociceptive target, although whether this will translate into humans remains to be determined, especially since expression in human sensory neurons has not been reported to date.

A further link with the central nervous system is seen in mouse cortical astrocytes, in which GPR35 mRNA was detected and kynurenic acid again inhibited forskolin-induced cAMP production, an effect that was abolished by either pre-treatment with the GPR35 antagonist CID-2745687 or GPR35 mRNA silencing by siRNA (Berlinguer-Palmini et al., 2013). Once more, however, it must be noted that CID-2745687 has been reported to be highly selective for the human ortholog of GPR35 (Jenkins et al., 2012) bringing into question the mode of action of this compound in a mouse model. In the same study, both kynurenic acid and zaprinast altered $\left[\mathrm{Ca}^{2+}\right]_{\mathrm{i}}$ waves in these cells and reduced evoked 
excitatory post-synaptic currents in rat hippocampal neurons. Although kynurenic acid also acts on $N$-methyl-D-aspartate and $\alpha 7$ nicotinic receptors, the effects on intracellular calcium signaling and synaptic currents were insensitive to antagonists of these receptors, but sensitive to CID-2745687. In addition, the cGMP phosphodiesterase inhibitor sildenafil failed to reduce synaptic currents. This strongly suggests that the effects of kynurenic acid and zaprinast reported in this study are due to their agonism of GPR35 and not other known targets of these ligands. It is, therefore, possible that GPR35 plays a role in rodent synaptic transmission, although, once again, these results are yet to be tested in human cell models. Nevertheless, GPR35 remains a potential therapeutic target in the treatment of pain or the prevention of excitotoxic damage.

\section{CONCLUSION AND FUTURE PERSPECTIVES}

The last few years have yielded significant advances in our understanding of GPR35 pharmacology and its physiological importance. Two major hurdles - a lack of pharmacological tools and significant species-selectivity - have been at least partially overcome, the former through the discovery and characterization of several novel synthetic ligands, and the latter through mutagenesis efforts that have provided insight into the cause of the species-selectivity, as well as the discovery of equipotent agonists. Future research efforts can now begin to assess the affinity of ligands for the receptor, which will be particularly useful in linking ligand-binding residues with functional capabilities. This has been made possible by the generation of the first radiolabeled ligand of GPR35: $\left[{ }^{3} \mathrm{H}\right]$ PSB-13253, which is an agonist with reported $\mathrm{K}_{\mathrm{D}}$ of $5.3 \mathrm{nM}$ at human GPR35 (Thimm et al., 2013). However, since this molecule is markedly human-selective, assessment of ligand affinity at the rodent receptors remains a challenge.

The increased repertoire of pharmacological tools can now be used to further probe GPR35 actions in physiological models. While current understanding makes GPR35 a promising candidate for therapeutic targeting given its involvement in a wide range of physiological and pathophysiological processes, no study has yet identified a definitive, targetable role for GPR35. This partially stems from a lack of tools; it is hoped that research efforts will now be directed toward the design of species equipotent antagonists, because the existing antagonists ML-145 (2-hydroxy-4-[4-(5Z)-5-[(E)-2-methyl-3-phenylprop-2enylidene]-4-oxo-2-sulfanylidene-1,3-thiazolidin-3-yl ]butanoylamino]benzoic acid) and CID-275687 (Heynen-Genel et al., 2010, 2011; Zhao etal., 2010) act with almost complete humanselectivity, and are of no practical use in rodent models (Jenkins et al., 2012). Equipotent antagonists would enable definitive conclusions about the therapeutic value of GPR35 to be drawn by providing a means to probe off-target effects in rodent disease models. However, much of the work described here focuses on only rodent models, and so future research should also aim to translate these findings into clinically relevant models in order to truly assess the therapeutic value of targeting GPR35.

\section{ACKNOWLEDGMENTS}

ND was funded by a Wellcome Trust Four-Year Ph.D. Studentship and AM was funded by a Biotechnology and Biological Sciences
Research Council Doctoral Training Grant in association with Medical Research Council Technology (grant number BBSRC DTG FO16735/1).

\section{REFERENCES}

Barth, M. C., Ahluwalia, N., Anderson, T. J., Hardy, G. J., Sinha, S., Alvarez-Cardona, J. A., et al. (2009). Kynurenic acid triggers firm arrest of leukocytes to vascular endothelium under flow conditions. J. Biol. Chem. 284, 19189-19195. doi: 10.1074/jbc.M109.024042

Berlinguer-Palmini, R., Masi, A., Narducci, R., Cavone, L., Maratea, D., Cozzi, A., et al. (2013). GPR35 activation reduces $\mathrm{Ca}^{2+}$ transients and contributes to the kynurenic acid-dependent reduction of synaptic activity at CA3-CA1 synapses. PLoS ONE 8:e82180. doi: 10.1371/journal.pone.0082180

Burkhardt, A. M., Tai, K. P., Flores-Guiterrez, J. P., Vilches-Cisneros, N., Kamdar, K., Barbosa-Quintana, O., et al. (2012). CXCL17 is a mucosal chemokine elevated in idiopathic pulmonary fibrosis that exhibits broad antimicrobial activity. J. Immunol. 188, 6399-6406. doi: 10.4049/jimmunol. 1102903

Choi, J. H., Kim, D. H., Yun, I. J., Chang, J. H., Chun, B. G., and Choi, S. H. (2007). Zaprinast inhibits hydrogen peroxide-induced lysosomal destabilization and cell death in astrocytes. Eur. J. Pharmacol. 571, 106-115. doi: 10.1016/j.ejphar.2007.06.042

Chopra, I. J., Williams, D. E., Orgiazzi, J., and Solomon, D. H. (1975). Opposite effects of dexamethasone on serum concentrations of 3,3',5'-triiodothyronine (reverse T3) and 3,3'5-triiodothyronine (T3). J. Clin. Endocrinol. Metab. 41, 911-920. doi: 10.1210/jcem-41-5-911

Civelli, O., Reinscheid, R. K., Zhang, Y., Wang, Z., Fredriksson, R., and Schiöth, H. B. (2013). G protein-coupled receptor deorphanizations. Annu. Rev. Pharmacol. 53, 127-146. doi: 10.1146/annurev-pharmtox-010611-134548

Cosi, C., Mannaioni, G., Cozzi, A., Carlà, V., Sili, M., Cavone, L., et al. (2011). Gprotein coupled receptor 35 (GPR35) activation and inflammatory pain: studies on the antinociceptive effects of kynurenic acid and zaprinast. Neuropharmacology 60, 1227-1231. doi: 10.1016/j.neuropharm.2010.11.014

Deng, H., and Fang, Y. (2012). Aspirin metabolites are GPR35 agonists. Naunyn Schmiedebergs Arch. Pharmacol. 385, 729-737. doi: 10.1007/s00210-0120752-0

Deng, H., Hu, H., and Fang, Y. (2011a). Tyrphostin analogs are GPR35 agonists. FEBS Lett. 585, 1957-1962. doi: 10.1016/j.febslet.2011.05.026

Deng, H., Hu, H., He, M., Hu, J., Niu, W., Ferrie, A. M., et al. (2011b). Discovery of 2-(4-methylfuran-2(5H)-ylidene)malononitrile and thieno[3,2-b] thiophene2-carboxylic acid derivatives as $\mathrm{G}$ protein-coupled receptor 35 (GPR35) agonists. J. Med. Chem. 54, 7385-7396. doi: 10.1021/jm200999f

Deng, H., Hu, H., and Fang, Y. (2012a). Multiple tyrosine metabolites are GPR35 agonists. Sci. Rep. 2, 373. doi: 10.1038/srep00373

Deng, H., Hu, J., Hu, H., He, M., and Fang, Y. (2012b). Thieno[3,2-b]thiophene2-carboxylic acid derivatives as GPR35 agonists. Bioorg. Med. Chem. Lett. 22, 4148-4152. doi: 10.1016/j.bmcl.2012.04.057

Drews, J. (2000). Drug discovery: a historical perspective. Science 287, 1960-1964. doi: 10.1126/science.287.5460.1960

Ellinghaus, D., Folseraas, T., Holm, K., Ellinghaus, E., Melum, E., Balschun, T., et al. (2013). Genome-wide association analysis in primary sclerosing cholangitis and ulcerative colitis identifies risk loci at GPR35 and TCF4. Hepatology 58, 1074-1083. doi: 10.1002/hep.25977

Fallarini, S., Magliulo, L., Paoletti, T., de Lalla, C., and Lombardi, G. (2010). Expression of functional GPR35 in human iNKT cells. Biochem. Biophys. Res. Commun. 398, 420-425. doi: 10.1111/j.1476-5381.2012.02108.x

Forrest, C. M., Gould, S. R., Darlington, L. G., and Stone, T. W. (2003). Levels of purine, kynurenine and lipid peroxidation products in patients with inflammatory bowel disease. Adv. Exp. Med. Biol. 527, 395-400. doi: 10.1007/978-1-4615-0135-0_46

Friberg, L., Werner, S., Eggertsen, G., and Ahnve, S. (2002). Rapid downregulation of thyroid hormones in acute myocardial infarction: is it cardioprotective in patients with angina? Arch. Intern. Med. 162, 1388-1394. doi: 10.1001/archinte.162.12.1388

Funke, M., Thimm, D., Schiedel, A. C., and Müller, C. E. (2013). 8Benzamidochromen-4-one-2-carboxylic acids: potent and selective agonists for the orphan G protein-coupled receptor GPR35. J. Med. Chem. 56, 5182-5197. doi: $10.1021 /$ jm400587g 
Garcia-Dorado, D., Agulló, L., Sartorio, C. L., and Ruiz-Meana, M. (2009). Myocardial protection against reperfusion injury: the cGMP pathway. Thromb. Haemost. 101, 635-642. doi: 10.1160/TH08-11-0764

Garland, S. L. (2013). Are GPCRs still a source of new targets? J. Biomol. Screen. 18, 947-966. doi: 10.1177/1087057113498418

Gashaw, I., Ellinghaus, P., Sommer, A., and Asadullah, K. (2011). What makes a good drug target? Drug Discov. Today 17, S24-S30. doi: 10.1016/j.drudis.2011. 09.007

Goodman, O. B. Jr., Krupnick, J. G., Santini, F., Gurevich, V. V., Penn, R. B., Gagnon, A. W., et al. (1996). Beta-arrestin acts as a clathrin adaptor in endocytosis of the beta2-adrenergic receptor. Nature 383, 447-450. doi: 10.1038/383447a0

Gotoh, M., Fujiwara, Y., Yue, J., Liu, J., Lee, S., Fells, J., et al. (2012). Controlling cancer through the autotaxin-lysophosphatidic acid receptor axis. Biochem. Soc. Trans. 40, 31-36. doi: 10.1042/BST20110608

Greene, S. J., Gheorghiade, M., Borlaug, B. A., Pieske, B., Vaduganathan, M., Burnett, J. C. Jr., et al. (2013). The cGMP signaling pathway as a therapeutic target in heart failure with preserved ejection fraction. J. Am. Heart Assoc. 2:e000536. doi: 10.1161/JAHA.113.000536

Guo, J., Williams, D. J., Puhl, H. L. III, and Ikeda, S. R. (2008). Inhibition of N-Type calcium channels by activation of GPR35, an orphan receptor, heterologously expressed in rat sympathetic neurons. J. Pharmacol. Exp. Ther. 324, 352-351. doi: 10.1124/jpet.107.127266

Hamilton, M. A., Stevenson, L. W., Luu, M., and Walden, J. A. (1990). Altered thyroid hormone metabolism in advanced heart failure. J. Am. Coll. Cardiol. 16, 91-95. doi: 10.1016/0735-1097(90)90462-X

Heynen-Genel, S., Dahl, R., Shi, S., Sauer, M., Hariharan, S., Sergienko, E., et al. (2010). Antagonists for the Orphan Receptor GPR35. Probe Report 1 and 2. La Jolla, CA: Sanford-Burnham Centre for Chemical Genomics.

Heynen-Genel, S., Dahl, R., Shi, S., Sauer, M., Hariharan, S., Sergienko, E., et al. (2011). Antagonists for the Orphan Receptor GPR35. Probe Report 3. La Jolla, CA: Sanford-Burnham Centre for Chemical Genomics.

Hopkins, A. L., and Groom, C. R. (2002). The druggable genome. Nat. Rev. Drug Discov. 1, 727-730. doi: 10.1038/nrd892

Horikawa, Y., Oda, N., Cox, N. J., Li, X., Orho-Melander, M., Hara, M., et al. (2000). Genetic variation in the gene encoding calpain-10 is associated with type 2 diabetes mellitus. Nat. Genet. 26, 163-175. doi: 10.1038/79876

Hüfner, M., and Grussendorf, M. (1978). Investigations on the deiodination of thyroxine (T4) to 3,3'-diiodothyronine (3,3'-T 2) in rat liver homogenate. Clin. Chim. Acta 85, 243-251. doi: 10.1016/0009-8981(78)90301-7

Iervasi, G., Pingitore, A., Landi, P., Raciti, M., Ripoli, A., Scarlattini, M., et al. (2003). Low-T3 syndrome: a strong prognostic predictor of death in patients with heart disease. Circulation 107, 708-713. doi: 10.1161/01.CIR.0000048124. $64204.3 \mathrm{~F}$

Imielinski, M., Baldassano, R. N., Griffiths, A., Russell, R. K., Annese, V., Dubinsky, M., etal. (2009). Common variants at five new loci associated with earlyonset inflammatory bowel disease. Nat. Genet. 41, 1335-1340. doi: 10.1038/ ng.489

Jacobson, L. H., Callander, G. E., and Hoyer, D. (2014). Suvorexant for the treatment of insomnia. Expert Rev. Clin. Pharmacol. 7, 711-730. doi: 10.1586/17512433.2014.966813

Jenkins, L., Alvarez-Curto, E., Campbell, K., de Munnik, S., Canals, M., Schlyer, S., et al. (2011). Agonist activation of the G protein-coupled receptor GPR35 involves transmembrane domain III and is transduced via $\mathrm{G} \alpha 13$ and $\beta$-arrestin-2. Br. J. Pharmacol. 162, 733-748. doi: 10.1111/j.1476-5381.2010.01082.x

Jenkins, L., Brea, J., Smith, N. J., Hudson, B. D., Reilly, G., Bryant, N. J., et al. (2010). Identification of novel species-selective agonists of the G-protein-coupled receptor GPR35 that promote recruitment of $\beta$-arrestin- 2 and activate G $\alpha 13$. Biochem. J. 432, 451-459. doi: 10.1042/BJ20101287

Jenkins, L., Harries, N., Lappin, J. E., MacKenzie, A. E., Neetoo-Isseljee, Z., Southern, C., et al. (2012). Antagonists of GPR35 display high species ortholog selectivity and varying modes of action. J. Pharmacol. Exp. Ther. 343, 683-695. doi: 10.1124/jpet.112.198945

Kuc, D., Zgrajka, W., Parada-Turska, J., Urbanik-Sypniewska, T., and Turski, W. A. (2008). Micromolar concentration of kynurenic acid in rat small intestine. Amino Acids 35, 503-505. doi: 10.1007/s00726-007-0631-z

Lukowski, R., Krieg, T., Rybalkin, S. D., Beavo, J., and Hofmann, F. (2014). Turning on cGMP-dependent pathways to treat cardiac dysfunctions: boom, bust, and beyond. Trends Pharmacol. Sci. 35, 404-413. doi: 10.1016/j.tips.2014.05.003
Luttrell, L. M., and Gesty-Palmer, D. (2010). Beyond desensitization: physiological relevance of arrestin-dependent signaling. Pharmacol. Rev. 62, 305-330. doi: 10.1124/pr.109.002436

Mackenzie, A. E., Caltabiano, G., Kent, T. C., Jenkins, L., McCallum, J. E., Hudson, B. D., et al. (2014). The antiallergic mast cell stabilizers lodoxamide and bufrolin as the first high and equipotent agonists of human and rat GPR35. Mol. Pharmacol. 85, 91-104. doi: 10.1124/mol.113.089482

Mackenzie, A. E., Lappin, J. E., Taylor, D. L., Nicklin, S. A., and Milligan, G. (2011). GPR35 as a Novel Therapeutic Target. Front. Endocrinol. (Lausanne) 2:68. doi: 10.3389/fendo.2011.00068

Maravillas-Montero, J. L., Burkhardt, A. M., Hevezi, P. A., Carnevale, C. D., Smit, M. J., and Zlotnik, A. (2014). Cutting edge: GPR35/CXCR8 is the receptor of the mucosal chemokine CXCL17. J. Immunol. 194, 29-33. doi: 10.4049/jimmunol.1401704

Milligan, G. (2011). Orthologue selectivity and ligand bias: translating the pharmacology of GPR35. Trends Pharmacol. Sci. 32, 317-325. doi: 10.1016/j.tips.2011.02.002

Min, K. D., Asakura, M., Liao, Y., Nakamaru, K., Okazaki, H., Takahashi, T., et al. (2010). Identification of genes related to heart failure using global gene expression profiling of human failing myocardium. Biochem. Biophys. Res. Commun. 393, 55-60. doi: 10.1016/j.bbrc.2010.01.076

Moroni, F., Cozzi, A., Sili, M., and Mannaioni, G. (2012). Kynurenic acid: a metabolite with multiple actions and multiple targets in brain and periphery. J. Neural Transm. 119, 133-139. doi: 10.1007/s00702-011-0763-x

Neetoo-Isseljee, Z., MacKenzie, A. E., Southern, C., Jerman, J., McIver, E. G., Harries, N., et al. (2013). High-throughput identification and characterization of novel, species-selective GPR35 agonists. J. Pharmacol. Exp. Ther. 344, 568-578. doi: 10.1124/jpet.112.201798

Neubig, R. R. (2010). Mind your salts: when the inactive constituent isn't. Mol. Pharmacol. 78, 558-559. doi: 10.1124/mol.110.067645

O’Dowd, B. F., Nguyen, T., Marchese, A., Cheng, R., Lynch, K. R., Heng, H. H., et al. (1998). Discovery of three novel G-protein-coupled receptor genes. Genomics 47, 310-313. doi: 10.1006/geno.1998.5095

Ohshiro, H., Tonai-Kachi, H., and Ichikawa, K. (2008). GPR35 is a functional receptor in rat dorsal root ganglion neurons. Biochem. Biophys. Res. Commun. 365, 344-348. doi: 10.1016/j.bbrc.2007.10.197

Oka, S., Ota, R., Shima, M., Yamashita, A., and Sugiura, T. (2010). GPR35 is a novel lysophosphatidic acid receptor. Biochem. Biophys. Res. Commun. 395, 232-237. doi: 10.1016/j.bbrc.2010.03.169

Paluszkiewicz, P., Zgrajka, W., Saran, T., Schabowski, J., Piedra, J. L., Fedkiv, O., et al. (2009). High concentration of kynurenic acid in bile and pancreatic juice. Amino Acids 37, 637-641. doi: 10.1007/s00726-008-0183-x

Prescott, R. W., Yeo, P. P., Watson, M. J., Johnston, I. D., Ratcliffe, J. G., and Evered, D. C. (1979). Total and free thyroid hormone concentrations after elective surgery. J. Clin. Pathol. 32, 321-324. doi: 10.1136/jcp.32.4.321

Rancoule, C., Dusaulcy, R., Tréguer, K., Grès, S., Attané, C., and SaulnierBlache, J. S. (2014). Involvement of autotaxin/lysophosphatidic acid signaling in obesity and impaired glucose homeostasis. Biochimie 96, 140-143. doi: 10.1016/j.biochi.2013.04.010

Rask-Andersen, M., Almén, M. S., and Schiöth, H. B. (2011). Trends in the exploitation of novel drug targets. Nat. Rev. Drug Discov. 10, 579-590. doi: $10.1038 / \mathrm{nrd} 3478$

Reilly, S. M., Chiang, S. H., Decker, S. J., Chang, L., Uhm, M., Larsen, M. J., et al. (2013). An inhibitor of the protein kinases TBK1 and IKK- $\varepsilon$ improves obesity-related metabolic dysfunctions in mice. Nat. Med. 19, 313-321. doi: 10.1038/nm.3082

Ronkainen, V. P., Tuomainen, T., Huusko, J., Laidinen, S., Malinen, M., Palvimo, J. J., et al. (2014). Hypoxia-inducible factor 1-induced G protein-coupled receptor 35 expression is an early marker of progressive cardiac remodelling. Cardiovasc. Res. 101, 69-77. doi: 10.1093/cvr/cvt226

Ryberg, E., Larsson, N., Sjögren, S., Hjorth, S., Hermansson, N. O., Leonova, J., et al. (2007). The orphan receptor GPR55 is a novel cannabinoid receptor. Br. J. Pharmacol. 152, 1092-1101. doi: 10.1038/sj.bjp.0707460

Sams-Dodd, F. (2005). Target-based drug discovery: is something wrong? Drug. Discov. Today 10, 139-147. doi: 10.1016/S1359-6446(04)03316-1

Schober, A., and Siess, W. (2012). Lysophosphatidic acid in atherosclerotic diseases. Br. J. Pharmacol. 167, 465-482. doi: 10.1111/j.1476-5381.2012. 02021.x 
Shonberg, J., Lopez, L., Scammells, P. J., Christopoulos, A., Capuano, B., and Lane, J. R. (2014). Biased agonism at g protein-coupled receptors: the promise and the challenges-a medicinal chemistry perspective. Med. Res. Rev. 34, 1286-1330. doi: $10.1002 / \mathrm{med} .21318$

Siehler, S. (2009). Regulation of RhoGEF proteins by G12/13-coupled receptors. $\mathrm{Br}$. J. Pharmacol. 158, 41-49. doi: 10.1111/j.1476-5381.2009.00121.x

Southern, C., Cook, J. M., Neetoo-Isseljee, Z., Taylor, D. L., Kettleborough, C. A., Merritt, A., et al. (2013). Screening $\beta$-arrestin recruitment for the identification of natural ligands for orphan G-protein-coupled receptors. J. Biomol. Screen. 18, 599-609. doi: 10.1177/10870571134 75480

Sun, Y. V., Bielak, L. F., Peyser, P. A., Turner, S. T., Sheedy, P. F. II, Boerwinkle, E., et al. (2008). Application of machine learning algorithms to predict coronary artery calcification with a sibship-based design. Genet. Epidemiol. 32, 350-360. doi: 10.1016/j.bbrc.2007.10.197

Tanabe, S., Kreutz, B., Suzuki, N., and Kozasa, T. (2004). Regulation of RGS-

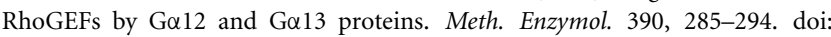
10.1016/S0076-6879(04)90018-3

Taniguchi, Y., Tonai-Kachi, H., and Shinjo, K. (2006). Zaprinast, a well-known cyclic guanosine monophosphate-specific phosphodiesterase inhibitor, is an agonist for GPR35. FEBS Lett. 580, 5003-5008. doi: 10.1016/j.febslet.2006.08.015

Thimm, D., Funke, M., Meyer, A., and Müller, C. E. (2013). 6-Bromo-8-(4$[(3) \mathrm{H}]$ methoxybenzamido)-4-oxo-4H-chromene-2-carboxylic acid: a powerful tool for studying orphan G protein-coupled receptor GPR35. J. Med. Chem. 56, 7084-7099. doi: 10.1021/jm4009373

Thorburn, A. N., Macia, L., and Mackay, C. R. (2014). Diet, metabolites, and "western-lifestyle" inflammatory diseases. Immunity 40, 833-842. doi: 10.1016/j.immuni.2014.05.014

Thumkeo, D., Watanabe, S., and Narumiya, S. (2013). Physiological roles of Rho and Rho effectors in mammals. Eur. J. Cell. Biol. 92, 303-315. doi 10.1016/j.ejcb.2013.09.002

Ueda, H., Matsunaga, H., Olaposi, O., and Nagai, J. (2013). Lysophosphatidic acid: chemical signature of neuropathic pain. Biochim. Biophys. Acta 1831, 61-73. doi: 10.1016/j.bbalip.2012.08.014

van Heerebeek, L., Hamdani, N., Falcão-Pires, I., Leite-Moreira, A. F., Begieneman, M. P., Bronzwaer, J. G., et al. (2012). Low myocardial protein kinase G activity in heart failure with preserved ejection fraction. Circulation 126, 830-839. doi: 10.1161/CIRCULATIONAHA.111.076075

Venkatakrishnan, A. J., Deupi, X., Lebon, G., Tate, C. G., Schertler, G. F., and Babu, M. M. (2013). Molecular signatures of G-protein-coupled receptors. Nature 494, 185-194. doi: 10.1038/nature11896
Wang, J., Simonavicius, N., Wu, X., Swaminath, G., Reagan, J., Tian, H., et al. (2006). Kynurenic acid as a ligand for orphan $\mathrm{G}$ protein-coupled receptor GPR35. J. Biol. Chem. 281, 22021-22018. doi: 10.1074/jbc.M603503200

Yang, Y., Fu, A., Wu, X., and Reagan, J. D. (2012). GPR35 is a target of the loop diuretic drugs bumetanide and furosemide. Pharmacology 89, 13-17. doi: $10.1159 / 000335127$

Yang, Y., Lu, J. Y., Wu, X., Summer, S., Whoriskey, J., Saris, C., et al. (2010). Gprotein-coupled receptor 35 is a target of the asthma drugs cromolyn disodium and nedocromil sodium. Pharmacology 86, 1-5. doi: 10.1159/000314164

Yoon, M. H., Choi, J. I., Bae, H. B., Jeong, S. W., Chung, S. S., Yoo, K. Y., et al. (2005). Lack of the nitric oxide-cyclic GMP-potassium channel pathway for the antinociceptive effect of intrathecal zaprinast in a rat formalin test. Neurosci. Lett. 390, 114-117. doi: 10.1016/j.neulet.2005.08.006

Zambrowicz, B. P., and Sands, A. T. (2003). Knockouts model the 100 best-selling drugs-will they model the next 100? Nat. Rev. Drug Discov. 2, 38-51. doi: $10.1038 /$ nrd987

Zhao, P., Lane, T. R., Gao, H. G., Hurst, D. P., Kotsikorou, E., Le, L., et al. (2014). Crucial positively charged residues for ligand activation of the GPR35 receptor. J. Biol. Chem. 289, 3625-3638. doi: 10.1074/jbc.M113.508382

Zhao, P., Sharir, H., Kapur, A., Cowan, A., Geller, E. B., Adler, M. W., et al. (2010). Targeting of the orphan receptor GPR35 by pamoic acid: a potent activator of extracellular signal-regulated kinase and $\beta$-arrestin 2 with antinociceptive activity. Mol. Pharmacol. 78, 560-568. doi: 10.1124/mol.110.066746

Conflict of Interest Statement: The authors declare that the research was conducted in the absence of any commercial or financial relationships that could be construed as a potential conflict of interest.

Received: 28 November 2014; paper pending published: 08 January 2015; accepted: 13 February 2015; published online: 10 March 2015.

Citation: Divorty N, Mackenzie AE, Nicklin SA and Milligan G (2015) G proteincoupled receptor 35: an emerging target in inflammatory and cardiovascular disease. Front. Pharmacol. 6:41. doi: 10.3389/fphar.2015.00041

This article was submitted to Pharmaceutical Medicine and Outcomes Research, a section of the journal Frontiers in Pharmacology.

Copyright (c) 2015 Divorty, Mackenzie, Nicklin and Milligan. This is an open-access article distributed under the terms of the Creative Commons Attribution License (CC BY). The use, distribution or reproduction in other forums is permitted, provided the original author(s) or licensor are credited and that the original publication in this journal is cited, in accordance with accepted academic practice. No use, distribution or reproduction is permitted which does not comply with these terms. 